\title{
ARTIGO
}

DOI

\section{O CURRÍCULO COMO RETÓRICA PROGRESSISTA DOS MOVIMENTOS POLÍTICOS NEOCONSERVADORES}

\author{
CURRICULUM AS PROGRESSIVE RETHORIC OF POLITICAL NEOCONSERVATIVES \\ MOVEMENTS
}

\author{
EL CURRÍCULO COMO RETÓRICA PROGRESISTA DE LOS MOVIMIENTOS \\ POLÍTICOS NEOCONSERVADORES
}

\author{
Paulo Sergio Marchelli \\ Universidade Federal de Sergipe - Brasil
}

\begin{abstract}
Resumo
O objetivo deste artigo é mostrar que as políticas curriculares são identificadas como progressistas ou conservadoras conforme a visão ideológica que dá hegemonia ao discurso de determinada corrente de pensamento. Para tanto, os fundamentos da teoria pós-estruturalista do discurso são utilizados como método para verificar os conflitos e convergências entre o Posmarxismo e o Neoliberalismo em termos do seu julgamento sobre a identidade política do currículo. Como resultado, o artigo apresenta a análise da conjuntura hegemônico-ideológica das principais correntes de pensamento sobre as políticas curriculares em voga no Brasil.
\end{abstract}

Palavras-chave: Políticas Curriculares Nacionais. Hegemonia e Ideologia. Conservadorismo e Progressismo.

\begin{abstract}
The objective of this paper is to show that the curriculum policies are identified as progressive or conservative according to the ideological vision that give hegemony to the speech of a particular school of thought. For this purpose, it uses the fundamentals of post-structuralist theory of discourse to check conflicts and convergences between post-Marxism and Neoliberalism in terms of judgment on the curriculum political identity. As a result, this paper presents an analysis of the hegemonic and ideological conjuncture of the main schools of thought about contemporary curricular policies in Brazil.
\end{abstract}

Keywords: National Curricular Policies. Hegemony and Ideology. Conservatism and Progressivism. 


\section{Resumen}

El objetivo de este artículo es mostrar que las políticas curriculares son identificadas como progresistas o conservadoras, según la visión ideológica que da hegemonía al discurso de determinada corriente de pensamiento. Para ello, los fundamentos de la teoría posestructuralista del discurso son utilizados como método para verificar los conflictos y convergencias entre el Posmarxismo y el Neoliberalismo en función de su valoración sobre la identidad política del currículo. Como resultado, el artículo presenta un análisis de la coyuntura hegemónico-ideológica de las principales corrientes de pensamiento sobre las políticas curriculares en auge en Brasil.

Palabras clave: Políticas Curriculares Nacionales. Hegemonía e Ideología. Conservadurismo y Progresismo.

\section{Introdução}

Há que se distinguir, inicialmente, em consideração à diferença entre ideias políticas conservadoras e progressistas, o fato de que as primeiras caracterizam uma visão de mundo formada por princípios e valores atemporais, que devem ser conservados diante de toda mudança histórica, de forma que a própria história parece ininteligível na falta de uma ordem divina que dá sustentação ao cosmos e fornece regras permanentes e seguras para o estabelecimento da harmonia necessária ao funcionamento da sociedade. Para os indivíduos conservadores, a racionalidade capaz de estabelecer regimes políticos estáveis deve fundamentar-se em uma ordenação moral assentada nas tradições formadas por valores familiares, princípios religiosos, patriotismo, entre outros em que se destacam formas diversas de contraposição entre a valorização e a restrição da liberdade individual. As diferenças sociais são entendidas pelos conservadores como naturais e até mesmo necessárias, de forma que não há como estabelecer um projeto político baseado na igualdade como forma universal de conceber as relações humanas, pois as tradições de cada povo são determinantes para a condução de sua história e a solução dos seus conflitos de ordem material (CONSERVADORISMO, 2016). Assim, os conservadores são não-deterministas e desconsideram as mudanças políticas como meios necessários para o progresso social, de forma que se 
opõem ao pressuposto do materialismo histórico, tornando-se reacionários frente a este e dispostos a combate-lo como o maior dos seus inimigos.

As ideias políticas progressistas, por sua vez, têm como princípio um conjunto de doutrinas filosóficas, éticas e econômicas que levam em conta a solução dos conflitos de ordem material como bases para o desenvolvimento da sociedade, de forma a entender deterministicamente o progresso histórico. A ideia de que as sociedades progridem da barbárie rumo à civilização de acordo com o desenvolvimento do conhecimento empírico que produz a ciência e a tecnologia foi forjada a partir do iluminismo europeu dos séculos XVII e XVIII, passando pela Revolução Industrial, pelo marxismo e chegando aos movimentos políticos atuais de aprimoramento dos direitos civis e individuais (PROGRESSISMO, 2016). pensamento progressista é em regra reformista e acredita que as condições necessárias à promoção do bem-estar humano são de natureza fundamentalmente política, que podem ser conquistadas por meio de transformações realizadas sobre a ordem econômica e social vigentes na sociedade.

Com base nas premissas expressas nos dois parágrafos acima, o objetivo do presente trabalho é apresentar uma discussão sobre os pontos de vista segundo os quais as políticas curriculares podem ser consideradas como progressistas ou conservadoras, de forma a estabelecer para isso alguns fundamentos conceituais que se mostram necessários. Para tanto, inspira-nos particularmente o texto de Lopes (2015), cujo propósito é operar com base na filosofia de Jacques Derrida a desconstrução inerente à lógica do discurso político, para depois reativar este mesmo discurso diante da perspectiva de Ernesto Laclau, fazendo emergir os antagonismos presentes nos sedimentos resultantes da desconstrução. "Todo texto está impregnado por um princípio desconstrutor, a desconstrução faz parte da lógica do texto" (DERRIDA, 2005, apud LOPES, 2015, p. 450). Depois da desconstrução, "o que se encontra sedimentado é sempre decorrente da decisão por uma alternativa, que vem de um ato de poder e não de uma suposta 
racionalidade obrigatória" (LACLAU, 1990, apud LOPES, 2015, p. 450). Interessa-nos, portanto, encontrar a forma lógica básica dos enunciados próprios às políticas do currículo para então questiona-los na perspectiva de ultrapassar sua retórica aparente e alcançar as ideologias profundas que Ihes imprimem a sustentação discursiva. Colocamo-nos, assim, diante do desafio final de descrever as disputas travadas pela apropriação dos significados políticos no campo do currículo no Brasil.

\section{Ideologia e retórica: uma digressão Althusser-Laclauniana}

É possível fazer uma distinção entre a retórica superficial presente de forma transitória para exprimir as disposições aparentes dos argumentos que constituem os discursos políticos e o sedimento linguístico mais profundo dos mesmos, que manifesta as verdadeiras intenções argumentativas por meio de suas representações ideológicas permanentes, essenciais e não dissolutas, que estabelecem sentidos e sem as quais a própria formulação discursiva se dissipa e perde o seu significado. A consideração de que a ideologia é o terreno onde os alicerces da linguagem política se sustentam foi concretizada no texto de Louis Althusser - Ideologia e Aparelhos Ideológicos do Estado -, essencial para a interpretação do marxismo. A explicação de que no capitalismo a ideologia é a principal força política do Estado compõem-se de três argumentos básicos:

1) Todos os Aparelhos de Estado funcionam simultaneamente pela repressão e pela ideologia, com a diferença de que o Aparelho (repressivo) de Estado funciona de maneira massivamente prevalente pela repressão, enquanto os Aparelhos Ideológicos de Estado funcionam de maneira massivamente prevalente pela ideologia; 2) enquanto 0 Aparelho (repressivo) de Estado constitui um todo organizado cujos diferentes membros estão subordinados a uma unidade de comando, a da política da luta de classes aplicada pelos representantes políticos das classes dominantes que detêm o poder de Estado, - os Aparelhos Ideológicos de Estado são múltiplos, distintos, 'relativamente autónomos' e susceptíveis de oferecer um campo objetivo a contradições que 
exprimem, sob formas ora limitadas, ora extremas, os efeitos dos choques entre a luta de classes capitalista e a luta de classes proletária, assim como das suas formas subordinadas; 3 ) enquanto a unidade do Aparelho (repressivo) de Estado é assegurada pela sua organização centralizada unificada sob a direção dos representantes das classes no poder, executando a política de luta de classes das classes no poder, a unidade entre os diferentes Aparelhos Ideológicos de Estado é assegurada, na maioria das vezes em formas contraditórias, pela ideologia dominante, a da classe dominante. (ALTHUSSER, 1980, p. 54)

A ideologia fornece energia aos mecanismos de dominação que existem no interior da sociedade de classes, força motriz onipresente mediante a qual os extratos sociais que detêm o poder político aparelham o Estado para garantir o funcionamento do sistema de produção capitalista. Para Marx, a ideologia age de forma a mascarar o significado da realidade. Sua ação é diferente dos aparelhos de Estado que funcionam por meio da ação repressiva, como o aparato policial, por exemplo, pois atua mediante a criação de formulações simbólicas que escondem a dominação e ocultam a realidade social, o que é encontrado particularmente na escola. No capitalismo, o sistema educativo forma tanto a mentalidade burguesa quanto a proletária, que na sociedade negociam o pagamento da força de trabalho destinada à operacionalização dos modos de produção. Assim, a produção de ideologia e fundamental para que na economia capitalista a exploração da força de trabalho operária pelos burgueses gere o lucro e a acumulação de capital.

Ao apresentar o populismo como um fenômeno que caracteriza parte considerável dos discursos mais eloquentes da história do capitalismo, Laclau realiza uma desconstrução pós-estruturalista da enunciação althusseriana, para fundamentar o que se denomina posmarxismo, sistema de linguagem política baseado na decodificação das relações sociais determinadas pela exploração do trabalho, geração do lucro e acumulação do capital na economia pós-industrial e neocapitalista moderna, que procura exprimir os 
novos significados que conceitos tal como o de ideologia adquiriram ao longo do percurso histórico do marxismo.

A 'ideologia' somente pode ser considerada como diferente da retórica envolvida na ação política se a retórica for entendida como um puro adorno de linguagem, que não afeta de modo algum os conteúdos transmitidos por esta. Esta é a concepção mais clássica de retórica, baseada em sua diferenciação com a lógica. O equivalente sociológico daquilo que se opõem a retórica é uma noção de atores sociais constituídos em torno de interesses bem definidos, que negociam de forma racional com o meio externo. Segundo esta visão de sociedade, a imagem dos agentes sociais cujas identidades se constituem em torno de símbolos populistas [neocapitalistas] difusos somente pode ser uma expressão de irracionalidade. [...]. Mas o que acontece se o campo da lógica falhar em sua constituição como uma ordem fechada e sejam necessários mecanismos retóricos para atingir este encerramento? Nesse caso, os mesmos mecanismos de retórica - metáfora, metonímia, sinédoque, catacrese - se tornam instrumentos de uma racionalidade social alargada e não podemos descartar a interpelação ideológica como meramente retórica. Assim, a imprecisão e o vazio dos símbolos políticos populistas [neocapitalistas] não podem ser anulados com facilidade: tudo depende do ato performativo que tal vazio vem a causar. (LACLAU, 2011, p. 25-6, grifos no original)

Althusser havia apontado como a ideologia funciona sem, no entanto, retirar-lhe a máscara com a qual esconde sua identidade. Laclau vê no discurso retórico o tecido de que esta máscara é feita e ao rompe-lo revela a face nua do novo capitalismo a mostrar sem pudor nuances de controle social historicamente insuspeitos. A sociedade neocapitalista gera por meio de suas contradições internas não mais a luta de classes tal qual anteriormente dada, mas uma disputa travada por grupos sociais que se exprimem de formas ora limitadas, ora extremas, por meio de sua sexualidade, raça, opções políticas, religiosidade e outras identidades amorfas. O posmarxismo pretende escrever para as minorias sociais um discurso político capaz de leva-las a cumprir seu destino histórico de fomentar as transformações sociais da pós-modernidade. No entanto, a posição de que a reconstrução do conceito de ideologia apresentada por 
Laclau aprofunda o discurso althusseriano não é o que em geral se lê na literatura especializada sobre a questão.

Veja-se, por exemplo, o ensaio de Motta e Serra (2014), que resgata a influência de Althusser sobre o pensamento laclauniano e aponta o conceito de ideologia como elo fundamental do diálogo entre os dois autores. $\bigcirc$ exame da contribuição de Laclau ao conceito de ideologia é apresentado no ensaio segundo dois eixos de análise. $O$ primeiro se ocupa de explicar a formulação original que Althusser dá ao conceito, definindo-o como o instrumento por meio do qual os representantes políticos das classes dominantes aparelham o Estado para deter o poder político. O outro eixo analítico reconhece que a teoria sobre o populismo-nacionalista de Laclau contribui para o entendimento do conceito de ideologia, mas ao fazê-lo submergir no interior das formulações discursivas também o "enterra", pois considera que a produção das representações imaginárias que visam a esconder do sujeito a realidade social em que vive é antes de ser ideológica uma realidade linguística. "No entanto, apesar de Laclau ter dado uma significativa contribuição ao conceito de ideologia, foi também um dos principais 'coveiros' desse conceito [...]" (MOTTA; SERRA, 2014, p. 126). ensaio desconsidera que o deslocamento da ideologia para o interior da linguagem torna seu entendimento ainda mais fundamental, pois permite reconhecer por meio de quais formas de discurso ela exprime o caráter de repressão a que se destina. Parece que o funcionamento dos mecanismos de desconstrução pós-estruturalistas é ignorado, pois eles não estão interessados em eliminar os conceitos que desconstroem, mas sim situa-los em uma dimensão que pretende ampliar seus significados. Dessa forma, o conceito de ideologia proposto por Althusser continua vivo, mesmo que os autores do ensaio não reconheçam a competência de Laclau para desconstruí-lo sem sepulta-lo:

Se a interpelação para Althusser é o mecanismo que materializa a ideologia nos sujeitos a partir dos aparelhos ideológicos, Laclau não aborda profundamente essa questão já que nem trata do papel dos aparelhos ideológicos, não

Revista Práxis Educacional, Vitória da Conquista - Bahia - Brasil, v. 14, n. 27, p. 280-309, jan./mar. 2018. 
obstante ainda que venha a reconhecer que a materialidade dos discursos advenha de rituais e práticas (embora ele não explicite sobre esses rituais e instituições no texto). (MOTTA; SERRA, 2015, p. 143).

A leitura da teoria do discurso desconstrutivista sobre a ideologia desvenda os mecanismos por meio dos quais os sistemas neocapitalistas de representação social são produzidos e inculcados como formas simbólicas concretas pelos novos AIE, como o shopping center que gera o consumismo pós-industrial e a manipulação política realizada pela imprensa na sociedade informacional. Na verdade, todo discurso político vale-se de formas ideológicas de representação da realidade social que visam a homogeneizar os conflitos de interesse da sociedade, seja ela herdeira do capitalismo, do socialismo ou de outros movimentos historicamente verificáveis. Portanto, os instrumentos de repressão simbólica vão muito além dos AIE e situam-se no arcabouço da própria linguagem que permeia as relações humanas. Foi por isso que Laclau não abordou diretamente a questão dos AIE, pois não caberia fazê-lo, desde que Althusser já os definiu claramente. São as bases para uma reinterpretação histórica do conceito de ideologia que a teoria do discurso laclauniana apresenta.

A pós-modernidade procura entender a política como uma produção simbólica aplicada à solução de conflitos de interesse, que enunciada por meio de discursos retóricos se constitui ideologicamente em todas as sociedades. Assim, em qualquer sociedade são produzidas retóricas de convencimento para repressão dos movimentos contra hegemônicos que perturbam a ordem social defendida pela maioria. E, como veremos a seguir, o currículo é sempre um instrumento repleto de ideologias, que serve ao controle social do Estado segundo os interesses políticos vigentes.

\section{A produção hegemônico-ideológica do currículo}

O livro Ideologia e Currículo de Michael W. Apple, cuja primeira edição foi publicada em 1979 nos Estados Unidos é considerado um dos mais 
importantes da história da educação ocidental. Baseado em um instrumental crítico e teórico constituído por análises culturais e políticas que permitiram explicar o funcionamento do currículo, do ensino e da avaliação de uma maneira ainda não pensada, o texto de Apple utiliza o conceito de ideologia em consonância com o pensamento althusseriano e também de acordo com a ideia de hegemonia, inicialmente formulada por Antonio Gramsci.

A hegemonia é o conjunto das práticas e expectativas geradas pelo emprego da energia nas tarefas humanas, que no capitalismo induz à ideia de que a divisão do trabalho resulta naturalmente em classes sociais com acessos diferenciados aos meios de produção, o que define direitos, deveres e estamentos políticos de poder distintos. Construída pelos significados e valores comuns experimentados reciprocamente pelos indivíduos no interior da sociedade de classes, a hegemonia dá a estes um sentido específico de realidade, além do qual não conseguem ir em direção a uma interpretação possível sobre as outras formas como a atividade econômica poderia se organizar. Na sociedade capitalista, as instituições de ensino são, em regra, os principais agentes de transmissão das representações que as classes dominantes fazem para mascarar os efeitos contraditórios da divisão do trabalho. Assim, a escola contribui de forma substancial por meio de uma tradição seletiva de conhecimentos para fazer com que as representações sobre a realidade sejam hegemônicas, eliminem as contradições implícitas da sociedade de classes e mantenham a divisão do trabalho economicamente produtiva. Para isso, a escola seleciona determinados significados e práticas, enquanto outros são negados e excluídos. A sucessiva reinvenção da ideologia é uma função precípua do currículo, que colabora para estabelecer os modelos hegemônicos de pensamento segundo os quais os indivíduos interpretam sistematicamente suas experiências vividas.

A maneira mais útil de pensar as características complexas, o alcance e as funções variadas da ideologia se encontra no conceito de hegemonia. A ideia de que a saturação 
ideológica permeia nossa experiência vivida nos capacita ver como as pessoas podem empregar modelos que tanto as ajudam a organizar seus mundos quanto as preparam para acreditar que são participantes neutras na instrumentalização neutra do ensino (como veremos, muito da linguagem empregada pelos educadores faz isso), embora ao mesmo tempo esses modelos sirvam a determinados interesses econômicos e ideológicos que lhes são ocultados. [...] a fim de ver como isso acontece devemos combinar as análises curriculares, sociopolíticas, econômicas e éticas de maneira que demonstrem as sutis conexões existentes entre a atividade educacional e tais interesses. (APPLE, 2006, p. 56)

Para que seja possivel formar continuamente os conhecimentos selecionados desde o início das experiências de aprendizagem dos alunos, torna-se necessário a "hegemonia ideológica", que Apple define como à inculcação de identidades sociais em sala de aula, que por serem hegemônicas confirmam-se no âmbito da vida política e posteriormente são recriadas no contexto do currículo que é colocado à escola. À medida que os alunos evoluem da pré-escola até a universidade, verbalizam seus pensamentos com mais facilidade e aprendem a assumir as representações referentes ao entendimento das identidades que Ihes são dadas como verdadeiras, de forma a se tornarem capazes de definir outras ideologias supostamente autônomas que legitimam as instituições sociais e a cultura com que interagem no dia-a-dia. Assim, os conhecimentos aprendidos pelos sujeitos enfatizam a natureza hegemônica da política dominante ao neles inculcar por meio da escola ideologias que produzem a ignorância necessária para encobrir os verdadeiros sentidos da vida social, de forma a apontar "para a naturalidade da aceitação, para os benefícios institucionais e para uma visão positivista, na qual o conhecimento está divorciado dos reais atores humanos que o criaram" (APPLE, 2006, P. 126). A nuvem de ignorância necessária para que o processo de dominação prevaleça é definido pelos agentes do AIE escolar, que sabem como tornar hegemônicos seus discursos, quase sempre enunciados por meio de linguagens construídas para atender aos fins de inculcação desejáveis. 
Desde que o livro Ideologia e Currículo se tornou um best-seller, a ideia de que a educação não é um ato politicamente neutro e que as ações empreendidas pelos educadores estabelecem as bases para que a escola enquanto AlE desenvolva as formas discursivas de consciência que dominam as economias altamente industrializadas, firmou-se na teoria educacional uma tradição coerente com a análise marxista de inspiração althusseriana. À página 35 da edição citada, Apple esclarece que sua forma de entender o problema da relação entre o currículo e a estrutura econômica, bem como o das conexões entre conhecimento e poder, "tornou-se cada vez mais uma questão estrutural". O autor também afirma no mesmo local do texto que cada vez mais tem buscado fundamentar a análise do problema estruturalista a que se refere por meio de "um conjunto de questões críticas geradas a partir de uma tradição neomarxista de argumentação", tradição que lhe parece oferecer o modelo mais persuasivo para organizar o pensamento contemporâneo concernente à educação.

Um aspecto presente na análise crítica empreendida pelo posmarxismo consiste no exame de como a distribuição e o consumo da riqueza gerada a partir do modo de produção capitalista são determinados pelas relações de poder estabelecidas em termos dos reflexos manifestos e latentes codificados nas estruturas de domínio sociorracial, machista, entre outros que representam o comando político-econômico das nações ricas de hegemonia branca, controladoras e organizadoras da vida cultural do planeta. Uma vez que as teorias críticas desenvolvidas a partir da segunda metade do último Século revelaram a face hegemônica-ideológica oculta do currículo, nos anos recentes a análise pós-marxista tem pretendido desvendar como as facetas que agora são confessas determinam nas práticas do cotidiano escolar formas de reprodução pedagógica induzidas em termos de conflitos ocasionados por relações de gênero, repulsões étnicas, preconceitos de cor, opções religiosas, escolhas políticas e convencionalismos culturais de minorias sociais como um todo. Para tanto, parece que as formas de interpretação fundadas nos textos que se 
constituíram a partir de premissas semelhantes às adotadas por ldeologia e Currículo não bastam e que mesmo a vertente pós-marxista deva ampliar seu campo reflexivo para acolher as formas de análise do discurso propostas pelos vieses radicais da fundamentação pós-estruturalista. O significado deste campo reflexivo tendo em conta uma breve apresentação do seu aporte epistemológico é o que se verá a seguir.

\section{A constituição discursiva do currículo}

Os atuais esforços para a pesquisa do currículo como texto político valem-se substancialmente das obras de Henry Giroux e Peter McLaren, que inspiram os estudos rotulados de pós-coloniais, pautados na ideia de que para além das teorias da reprodução que se tornaram referências fundamentais nas décadas dos anos de 1970 e 1980, haveria que se considerar o conceito de resistência em educação como a autonomia relativa que a escola adquire na produção de significados quando se põe a ensinar criticamente as relações entre classe social e cultura. Nessa perspectiva, "é possível entender o currículo como um espaço-tempo de fronteira cultural no qual a colonização não é operada pelo professor sobre o aluno, ou ainda do conhecimento científico sobre o cotidiano" (LOPES; MACEDO, 2013, p. 25). Ao dar significado ao conceito de resistência como ação contra hegemônica à aceitação dos valores capitalistas associados à divisão social do trabalho, a escola desenvolve posições anti-ideológicas vindas principalmente de alunos marginalizados que manifestam sua contestação aos sentidos culturais dominantes (GIROUX, 1986). As teorias da resistência visam principalmente a fundamentar as transformações pedagógicas necessárias para que compromissos de emancipação política surjam no cotidiano da escola a partir das contradições refletidas pelos sujeitos. Esta emancipação, por sua vez, ancora-se na ideia da formação da consciência crítica como condição de combate às ideologias de 
dominação e submissão presentes no discurso reprodutor das desigualdades sociais que são elaborados pela escola.

Ao criar o discurso da reprodução para mascarar as contradições inerentes aos antagonismos resultantes das desigualdades sociais, a escola precisa elaborar construções de linguagem que expõem invariavelmente antinomias lógicas e retóricas persuasivas. Assim, como resposta dialética, são criados outros discursos, desta vez contra hegemônicos, que atendem às demandas de como dotar a escola de mecanismos de resistência voltados para a emancipação do trabalho pedagógico frente à reprodução ideológica. Esses novos discursos se constituem com base na premissa de que a consciência de emancipação possível de ser formada pela escola prevalece frente a dominação cultural, que nunca é tão fortemente poderosa a ponto de impedir a insurgência de formas típicas de resistência, pois nenhuma superioridade consegue esconder por completo a diferença e a desigualdade social. Para a interpretação dos mecanismos que surgem na contramão da reprodução cultural, os aportes teóricos pós-coloniais se valem da teoria do discurso de Ernesto Laclau, pela qual procuram explicar como os professores e alunos que atuam no contexto da escola, ao se defrontarem criticamente com os processos opressivos por meio dos quais se tornam agentes do colonialismo, também atuam na produção da diferença. Isso porque a teoria do discurso laclauniana permite explicitar como ao se constituir dialeticamente diante das teses da reprodução o sujeito desenvolve a resistência como uma antítese poderosa que o faz tomar consciência de suas ações políticas. A nova consciência decorre, portanto, das crises verificadas diante das fraquezas da velha ordem que ainda quer se impor, mas está desgastada para tanto.

Em muitas ocasiões o discurso de uma 'nova ordem' é aceito por numerosos setores sociais, não porque eles se sintam particularmente atraídos por seu conteúdo concreto, mas sim porque é um discurso de algo que se apresenta como alternativa crível frente às crises e às deslocações generalizadas. (LACLAU, 2000, p.82) 
A noção de deslocação é utilizada por Laclau para se referir à debandada para o interior das estratégias socialistas dos princípios que elas historicamente cuidaram de tornar hegemônicos com vistas a garantir a prevalência das formas não capitalistas de produção material trazidas pela revolução marxista. Assim, em nome de uma democracia radical que vai além do capitalismo e do projeto socialista de produção econômica, Laclau parte para a desconstrução do marxismo, mediante o argumento de que este adquiriu ao longo de sua história categorias de hegemonização política pautadas em deslocações ideológicas que geraram antagonismos conflitantes e suscitaram revoluções democráticas. Na perspectiva laclauniana, a centralidade crescente de categorias ideológicas hegemônicas nas nações socialistas subverteu a lógica do discurso marxista e sua visão sobre o movimento dialético do determinismo histórico rumo a uma sociedade economicamente justa e igualitária. Assim, os antagonismos ideológicos deslocados para o interior do socialismo real impediram que "nenhuma teorização positiva acerca da 'objetividade' de agentes históricos (tal como, por exemplo, a luta de classes), fosse fixada no terreno da reconstrução política das identidades sociais" (LACLAU, 2000, p. 21).

Portanto, o sujeito se constitui pela ação política e por meio dela não Ihe é possível identificar-se de outra forma que não seja discursivamente. A emancipação também não poderá existir fora da ação política, pois é construída na medida em que o sujeito inclui no projeto emancipatório a perspectiva de garantir a resistência necessária para controlar as demandas oriundas dos conflitos resultantes da relação capital-trabalho, bem como esgarçar o tecido que mascara a consciência da desigualdade na produção e distribuição da riqueza. Problemas como a liberdade para criação da identidade de gênero que legitima opções sexuais diferenciadas, superação da ideologia de raça, cor e tantas outras questões pensadas como realizações políticas incontingentes nas nações socialistas, não conseguiram historicamente se colocar no centro do universal político das mesmas e tal qual na sociedade de classes somente se hegemonizaram 
como lutas contingenciáveis e provisórias. "Nesse sentido, uma proposta emancipatória de currículo não se encontra no real para ser desvelada, não se encontra no futuro para ser alcançada, nem depende de um sujeito consciente e centrado para ser defendida" (LOPES; MACEDO, 2013, p. 26). Assim, o currículo emancipatório é sempre uma proposta construída como discurso para previsão das lutas culturais e políticas nas quais as demandas sociais e os processos de identificação das individualidades devem ser contemplados sem que, no entanto, se possa conhecer o destino fugidio e furtivo que as indeterminações históricas reais lhes imporão. Nesse sentido, Laclau parece ter contribuído definitivamente para que os curriculistas acrescentem em suas tarefas o exercício de confrontarem as retóricas discursivas das quais seu ofício impreterivelmente se vale.

\section{Inflexões progressistas e neoconservadoras no discurso democrático sobre o currículo}

Há que se diferenciar primeiramente entre a retórica e a ideologia enquanto partes constituintes dos movimentos políticos para alçar as formas emergentes de análise do currículo a partir da teoria do discurso laclauniana:

[...] debemos distinguir cuidadosamente entre la retórica utilizada por los miembros de un movimiento - la cual puede ser plagiada de un modo aleatorio de cualquier parte, según las necesidades del movimiento -, y la ideologia, que expresa la corriente más profunda del movimento. (MINOGUE, 1969, apud LACLAU, 2011, p. 24, grifos no original).

A retórica distingue-se assim da ideologia pela diferença que ambas adquirem na formulação do discurso político, referindo-se a primeira às regras morfológicas e sintáticas da gramática que ditam a forma lógica aparente e superficial dos enunciados linguísticos, enquanto a outra diz respeito aos significados semânticos profundos adquiridos por aqueles 
enunciados nos diferentes contextos em que possam ser materializados. No sentido deleuziano da diferença, a retórica e a ideologia distinguem-se uma da outra como, por exemplo, "o relâmpago distingue-se do céu negro, mas deve acompanhá-lo, como se ele se distinguisse daquilo que não se distingue" (DELEUZE, 2006, p. 36). Talvez outra metáfora possa significar mais, dizendo que a ideologia e a retórica se produzem na política como a água que corre rio abaixo forma uma correnteza sem a qual o rio não manteria seu curso. Assim, para formar a torrente do discurso político, a retórica que está na superfície desce à profundidade da ideologia sem deixar de ser superficial, ao mesmo tempo em que a ideologia sobe à tona para compor a retórica discursiva sem deixar de ser profunda. Em tempos pós-coloniais, não há como desconsiderar que os princípios filosóficos-metafísicos que fundamentam a política precisam ser relativizados em termos da sua enunciação discursiva, nem há como desconhecer que a existência de movimentos políticos na empiria do mundo real depende do discurso que Ihes dá forma e conteúdo. A retórica e a ideologia são pois respectivamente a forma e o conteúdo do discurso político, que se misturam no interior deste para a ele dar passagem como o rio que forma o curso dentro do qual a água corre.

Enxergar a diferença entre a ideologia e a retórica com olhos metafóricos cabe bem à visão pós-estruturalista de Jacques Derrida, que na sua análise da linguagem escrita mostra como o jogo da sombra contra a luz que se dá no mostrar-se e no esconder-se se encontra presente na origem da filosofia ocidental.

[...] metáfora fundadora da filosofia ocidental como metafísica. Metáfora fundadora não apenas enquanto metáfora fotológica - e nesse aspecto toda a história da nossa filosofia é uma fotologia, nome dado à história ou ao tratado da luz - mas já enquanto metáfora: a metáfora em geral, passagem de um sendo o outro, ou de um significado a outro, autorizado pela submissão e pela deslocação analógica do ser sob o sendo, é o peso essencial que retém e detém irremediavelmente o discurso da metafísica. (DERRIDA, 1995, p. 48, grifos no original). 
Assumindo assim como princípio que a ideologia e a retórica estão presentes nos fundamentos metafísicos do discurso que alicerça os movimentos políticos, pode-se partir para a pesquisa sobre como tais fundamentos funcionam no campo específico constituído pelas políticas curriculares, que nas sociedades de classes são instrumentos fundamentais dos AIE escolares. Nas sociedades que se mexeram em direções anticapitalistas por meio de movimentos políticos de bases socialistas, as políticas curriculares sofreram uma progressiva deslocação para legitimar dentro daquelas sociedades a hegemonia que lhes é própria.

No que diz respeito ao discurso sobre os fundamentos ideológicos do currículo, talvez ninguém melhor do que Michael Apple tenha iniciado uma análise que se tornou concisa para uma particular observação sobre a pedagogia conservadora das escolas norte-americanas nos anos que antecederam a virada do Século XXI e que depois se ampliou nos anos sucessivos. No prefácio escrito em 2004 para a terceira edição de Ideologia e Currículo, comemorativa dos 25 anos desde que o festejado livro foi publicado pela primeira vez, Apple se mostra surpreendido com os crescentes ataques realizados pelas forças conservadoras a qualquer coisa que seja pública nos EUA, o que constitui uma faceta de dominação típica das novas articulações de poder político que surgiram naquela sociedade. "O neoliberalismo e o neoconservadorismo estão na posição de comando agora, e não apenas na educação. [...]. Entretanto, as relações de classe não explicam integralmente as razões para essa situação" (APPLE, 2006, p. 11-12). Diante do interesse na formação de uma força de trabalho altamente especializada a serviço do capitalismo financeiro, os currículos e exames nacionais produzidos pelas políticas educacionais neoliberais e neoconservadoras tornaram-se instrumentos que elevaram o nível de aparelhamento da escola para um controle ideológico total sobre os indivíduos, que tenta lhes retirar todo poder de resistência. Para mascarar os efeitos discriminatórios e de exclusão que tais políticas produzem no interior 
da sociedade submissa às novas formas do sistema capitalista que estão a surgir, nisso os EUA são pródigos, impõe-se a retórica de que com o neoliberalismo os mais pobres passam a ser ajudados, porque lhes é permitido ter mais autonomia para governarem suas vidas. A condição que dava aos trabalhadores a possibilidade de se representarem como uma classe social hegemônica dissipou-se por meio das políticas neoliberais em segmentos estratificados por categorias de gênero, raça, religião e outras formas possíveis de constituição segmentada da identidade. Essa ruptura da hegemonia da classe trabalhadora impôs para ela dentro da economia neoliberal uma forma de participação nos bens de produção que também é diferenciada em termos das estratificações a que se submeteu, o que determina seu acesso a empregos decentes, à saúde pública, à educação e a tantas outras coisas. "Por questões de economia, saúde, educação, nutrição, etc., as cidades norte-americanas são em geral um lugar perigoso para as crianças negras e para as crianças 'latinas', não só para o seu presente, mas também para o futuro" (APPLE, 2006, p. 12). Para que o novo capitalismo não logo se dissipe à escola cabe como forma de ação contingencial e provisória produzir retóricas ideológicas que tentem sustentar a divisão do trabalho na sociedade informacional. Diante disso, os aportes teóricos pós-coloniais voltam-se para a questão de saber como as políticas contra hegemônicas são construídas.

[...] é possível fazer algo diferente, que interrompa as políticas e ideologias neoliberais e conservadoras, que tenha uma política muito diferente de conhecimento legítimo e seja baseado em um real compromisso de criar escolas intimamente relacionadas a um projeto maior de transformação social? Penso que sim. (APPLE, 2006, p. 13)

Apple recorre a um exemplo acontecido aqui no Brasil, país em que a partir da metade da década dos anos 1980, depois que o governo militar apoiado pelos Estados Unidos se extinguiu, trabalhou com educadores progressistas e socialmente críticos, estabelecendo em particular com Paulo Freire uma intensa colaboração (AS CONTRIBUIÇÕES DE PAULO FREIRE, 2006). 
Nessa época, uma colaboração não menos intensa foi realizada com o Partido dos Trabalhadores (PT), o qual Apple ajudou a pensar e construir uma educação digna no Brasil. Uma experiência marcante que ele relata foi o conjunto de políticas democráticas e coerentes que o PT desenvolveu na cidade de Porto Alegre, como o Orçamento Participativo e a Escola Cidadã, por meio das quais atraiu um grande número de eleitores que antes votavam em partidos conservadores, mantendo-se assim no poder municipal de 1989 até 2004. Na educação, uma política importante do PT em Porto Alegre naquele período foi promover aumentos substanciais dos salários dos professores. Mas foram os atos de compartilhamento do poder com todos os estratos sociais, desde pessoas que viviam nas favelas, passando pelas classes trabalhadora e média e chegando aos profissionais liberais, como por exemplo os professores, que fornecem as maiores evidências de que uma democracia substancialmente progressista interpõe alternativas contra hegemônicas concretas às visões políticas socialmente retrógradas praticadas pelo conservadorismo tradicional. $\bigcirc$ que aconteceu em Porto Alegre constitui, assim, uma experiência crucial de pedagogia radical não somente para os educadores brasileiros, como também para as outras partes do mundo.

No entanto, as experiências educacionais contra a hegemonia capitalista oriundas do tipo de democracia radical praticada pelo PT em Porto Alegre não resistiram ao teste do tempo. As gestões municipais seguintes foram levadas a retroagir para condições muitas vezes nada progressistas. O próprio PT encontra-se no ano de 2016 esfacelado por contradições adquiridas ao longo do período em que conviveu com o capitalismo neoliberal, do qual adquiriu vícios que minaram seu projeto político original. Muitos dos membros do PT se corromperam para garantir o poder e os que resistiram estão a ver seu contingente de eleitores diminuir substancialmente.

O sentido que Apple dá ao conceito de democracia radical é diferente daquele encontrado no posmarxismo descrito como movimento 
político por Laclau. Para este, conforme vimos anteriormente, a democracia radical é pensada além do projeto socialista de produção econômica, o que representa a desconstrução do marxismo. As reflexões laclaunianas sobre as revoluções do nosso tempo sustentam-se no fato empírico de que os países que implantaram governos socialistas adquiriram ao longo de sua história categorias de hegemonização ideológica pautadas em deslocações autoritárias que geraram antagonismos sociais conflitantes e suscitaram transformações democráticas que reinstalam o capitalismo de Estado. No entanto, para ambos os autores, a ideia de uma ampla participação dos indivíduos na política é semelhante.

De uma forma geral, tanto os Estados com histórico socialista quanto os que se mantiveram capitalistas estão a realizar uma democratização radical da sociedade, que emerge de uma variedade de lutas autônomas determinadas por formas de articulação hegemônicas dependentes da proliferação de espaços públicos de argumentação e decisão políticas, por meio dos quais os indivíduos se articulam para se tornarem crescentemente capazes de assumir a gestão de seus próprios interesses. O caminho encontrado para essa radicalização consubstanciada como uma reforma política que procura democratizar o liberalismo econômico passou a ser denominado de neoliberalismo. Essa reforma envolve basicamente a consolidação do sistema de sufrágio universal por meio da ampliação dos princípios éticos que sustentam o debate sobre os rumos da sociedade, promove o aumento da divisão dos poderes político-administrativos que tomam as decisões dobre a gestão do Estado, realiza o aprofundamento da independência entre esses poderes, a valorização do multipartidarismo, a amplo respeito aos direitos humanos e civis, etc. "É dentro do marco destes princípios básicos da comunidade política que é possível fazer avançar o amplo arco de reivindicações democráticas atuais (desde os direitos das minorias nacionais, raciais e sexuais, até a própria luta anticapitalista" (LACLAU, 2000, p. 144). 
Estas considerações nos levam a julgar que é mais sensato responder não ou talvez à questão para a qual Apple respondeu sim, negando ou colocando em dúvida a possibilidade de que haja algo concreto capaz de interromper as práticas neoconservadoras que acometem hoje as políticas educacionais em tantos países do mundo. Talvez seja possível civilizar essas práticas que se impõem como monstros históricos misteriosos que ressuscitaram da velha ordem econômica. Mas elas foram construídas no bojo das transformações democráticas que inflexionam o posmarxismo político em direção ao neoliberalismo econômico e estão se tornando hegemônicas como base institucional da maior parte dos Estados contemporâneos. Procuraremos demonstrar a seguir, considerando as políticas curriculares brasileiras atualmente em debate, como elas se apresentam segundo uma historicidade em que retóricas com diferentes ideologias conservadoras e progressistas convergem para uma mesma forma de homogenia social, que compõem uma sociedade onde os traços do marxismo e do neoliberalismo antes conflitantes agora se inflexionam um para o outro. Constitui-se assim o neoliberalismo associado ao posmarxismo, que dilui as diferenças ideológicas e descoloca para dentro da discussão política conservadores e progressistas, guiados respectivamente pelo capitalismo tradicional ou pelo anticapitalismo.

\section{A retórica discursiva das políticas curriculares neoconservadoras no Brasil}

Inicialmente, vejamos que Laclau apresenta o posmarxismo como uma desconstrução que atribui ressignificação ao marxismo diante das mudanças que este sofreu ao longo do seu trânsito histórico.

La transición de uno a otro podría ser caracterizada como una ampliación de horizontes. Del mismo modo que las geometrías no euclidianas no niegan la geometría de Euclides sino que la presentan como caso especial dentro de un universo de alternativas más amplias, las categorías básicas del marxismo deben ser presentadas como formas históricas específicas 
dentro de un universo más amplio de articulaciones posibles. (LACLAU, 2000, p. 177)

Vejamos também que a palavra anticapitalismo é utilizada para dar significado à ampla variedade de posições intelectuais que fazem do capitalismo uma doutrina a ser sepultada no passado das ideias sobre a ciência econômica. Já neocapitalismo refere-se à desconstrução dos significados correntes do capitalismo antes dos anos de 1970, quando os conflitos entre capital e trabalho ainda não eram prioritariamente tratados entre os sindicatos, o governo e as empresas privadas como uma negociação visando à melhoria dos níveis de salário, ao aperfeiçoamento de programas sociais, ao avanço dos estamentos voltados aos direitos democráticos do trabalhador, às políticas previdenciárias, etc. $\bigcirc$ neoliberalismo, que é uma revisão desconstrutiva do liberalismo clássico não se opõe ao neocapitalismo. Fundamentalmente, o posmarxismo se opõe ao neoliberalismo e este ao anticapitalismo, que se opõe ao neocapitalismo. No entanto, o posmarxismo, o neoliberalismo e o neocapitalismo convivem dentro da mesma democracia radical que vem ampliando na pósmodernidade a vigilância das sociedades mundiais sobre a política.

No Brasil, encontram-se nesse momento na pauta da discussão política alguns projetos curriculares de reforma educacional alçados em uma ampla participação da sociedade por meio de canais democrático-radicais que inflexionam propostas neoliberais típicas em direção ao posmarxismo resultante do processo de ascensão do PT ao poder central. Sobre o posmarxismo petista, enquanto ocupou o poder central desde o ano de 2003 pode-se dizer ter sido mais capitalista do que anticapitalista, por isso talvez tenha sido expulso por meio de um inexplicável golpe parlamentar conservador em 2016. As forças conservadoras que se instalaram no poder estavam no primeiro momento com sede de ressuscitar um tipo de capitalismo ligado ao passado, que por ignorância acreditavam fazer parte do neoliberalismo atual que tanto os incitava. Ledo engano, pois logo que tentaram aprovar suas primeiras medidas reformistas renderam-se a uma 
sociedade aparelhada com vigilante resistência e aprenderam a encarar a verdadeira face do neoliberalismo, muito mais anticapitalista do que eles imaginavam. Julgaram que deveriam oferecer nossos recursos econômicos para uma exploração selvagem do capital internacional com vistas a que as contas do Estado brasileiro voltassem a ter equilíbrio, mas foram coagidos a manter os programas sociais tal como a Bolsa-Família do PT. Suas reformas pensadas inicialmente apenas em termos de enxugar o investimento de recursos públicos na educação, aos poucos passaram a colocar no centro das formulações políticas a perspectiva da inclusão social e da qualidade de ensino. Isso mostra que o movimento anticapitalista é uma circunstância de ampla hegemonia na revolução democrática brasileira, mesmo que o posmarxismo tenha sido alijado do poder.

Consideremos a Base Nacional Comum Curricular (BNCC ou Base), que tanto aos olhos mediáticos dos marxistas e pós-marxistas conservadores que the deram as feições iniciais e submeteram-na à consulta pública em 2015, quanto aos olhos incertos dos neoliberais de plantão que a mantêm hoje em discussão, representa o maior progresso pelo qual a educação brasileira poderia passar na presente década (MERCADANTE, 2016; AGUIAR, 2016). Já as vozes de marxistas e pós-marxistas moderados e progressistas sediados na academia brasileira não têm se calado para alertar contra as feições políticas retrógradas que aos seus olhos a Base reproduz (ALVES, 2014; MACEDO, 2014; MARCHELLI, 2014; PONCE, 2016). A visão sobre a Base corresponde, assim, a um fator fundamental de hegemonia ideológica que diferencia as duas principais correntes de discurso político, o qual mediante formas cujo tom varia entre a moderação e o radicalismo participam hoje do direito ao debate e à disputa pelo poder na democracia brasileira. Por um lado, há os que se fundamentam em um neoliberalismo do tipo conservador, que diz ser a Base um remédio de salvação para nossos problemas educacionais e, de outro, os marxistas e pós-marxistas considerados progressistas, que assumem posições moderadas ou radicais para tentar demonstrar que, ao contrário, a Base é um antídoto que 
favorece nossas históricas contradições sociais. O notável é que diante de suas possíveis formas de enunciação no quadro das representações políticas, - currículo é hoje na democracia brasileira um fator de conjugação hegemônica dos grupos partidários mais importantes, por meio do qual lhes é permitido demarcarem-se ideologicamente e debaterem suas posições utilizando sintagmas de extraordinário poder retórico.

Diante dos objetivos do presente artigo, a nós cabe para finaliza-lo investigar a retórica das políticas conservadoras sobre o currículo, deixando para outro momento indagar sobre a voz dos progressistas a esse respeito. Apenas lembramos que em Marchelli (2016) é apresentado um quadro analítico que contempla as metas para a Ensino Médio brasileiro presentes na reforma estabelecida pelo Plano Nacional de Educação (PNE), que mostra como há consensos hegemônicos sobre os quais se tinha certeza representarem o pensamento progressista, oriundos de um longo debate político, mas que acabaram por pressupor determinados indicadores educacionais falaciosos como verdadeiros. Dessa forma, os consensos políticos progressistas quando se mostram falsos não deveriam ser identificados como conservadores e vice-versa? A resposta parece ser não, desde que é mais interessante assumir que a contraposição entre conservadores e progressistas na sociedade não é dicotômica, pois isso garante o livre juízo de pensar que em todos os gêneros de movimentos políticos (posmarxismo, neoliberalismo, neocapitalismo, etc.) é possível encontrar tanto ideias neoprogressistas quanto neoconservadoras. Os consensos hegemônicos são ideológicos e não têm uma identidade progressista ou conservadora própria, apenas sua retórica é capaz de mantê-los vivos para serem ouvidos. E a retórica, não poderia ser metaforizada na teoria do discurso curricular de outra forma a não ser como:

[...] o desejo da exterioridade da presença e da não-presença. Essa exterioridade é uma matriz. Entre todos seus representantes [encontram-se] a exterioridade da natureza e de seus outros, do bem o do mal, da inocência e da perversidade, da consciência e da não-consciência, da vida e 
da morte, etc. [...]. É a exterioridade da servidão e da nãoservidão, ou da liberdade e da não-liberdade. [Ela] reúne mais claramente que outros o histórico, o político, o econômico, o técnico e o metafísico. (DERRIDA, 2006, p. 204)

Para Aristóteles há "três espécies de retórica ou gêneros de discurso: judicial ou forense, deliberativo ou político e demonstrativo ou epidíctico" (ARISTÓTELES, 2005, p. 38). A BNCC reflete de forma fiel a natureza da nova democracia brasileira, que é inteiramente fundamentada no discurso jurídico. As sucessivas versões apresentadas pelo Ministério da Educação (MEC) aos propósitos do debate democrático antes da data ainda incerta em que uma variante final deverá ser colocada em votação pelos representantes do poder legislativo nacional, ditam pela força da lei o que é obrigatório de ensinar e aprender:

Ao deixar claros os conhecimentos essenciais, a que todos os estudantes brasileiros têm $o$ direito de acesso e de apropriação durante sua trajetória na Educação Básica, desde o ingresso na Creche até o final do Ensino Médio, a Base Nacional Comum Curricular (BNCC) constitui-se parte importante do Sistema Nacional de Educação. Configura-se como parâmetro fundamental para a realização do planejamento curricular, em todas as etapas e modalidades de ensino, a ser consolidado no Projeto Político Pedagógico (PPPs) das Unidades Educacionais (UEs), de acordo com 0 inciso l, do artigo 12, da Lei 9.394 (LDB). No processo de implementação da BNCC, como norma que deve subsidiar a elaboração de currículos, e em consonância com as Diretrizes Curriculares Nacionais Gerais para a Educação Básica, recomenda-se estimular a reflexão crítica e propositiva, que deve subsidiar a formulação, execução e avaliação do projeto político-pedagógico da escola de Educação Básica face a esta norma. (MEC, 2016, p. 30)

O uso da palavra direito na segunda linha da citação acima é uma catacrese, pois não descreve com exatidão o que se quer exprimir. Na verdade, a Base expõe os conhecimentos essenciais que todos os estudantes brasileiros têm o dever de aprender durante sua trajetória na Educação Básica. E não é apenas em figuras retóricas desse tipo que reside a verdadeira identidade política do discurso da BNCC, que está nos sofismas

Revista Práxis Educacional, Vitória da Conquista - Bahia - Brasil, v. 14, n. 27, p. 280-309, jan./mar. 2018. 
formados por raciocínios capciosos, falácias, silogismos aparentes e outros, que ocultam um verdadeiro sentido neoconservador. Não são os direitos, mas sim os deveres da escola que interessam ao neoconservadorismo voltado para o restabelecimento do capitalismo de exploração no lugar do neocapitalismo redistributivo. Da mesma forma, são os deveres que devem ser ensinados a favor do poder do Estado que interessam aos marxistas neoconservadores, que se opõem ao direito de pensar livremente sobre o sentido da história que caracteriza o progresso do posmarxismo. Assim também, o liberalismo clássico pretende que a escola se ocupe de conservar como absoluto o princípio de que o Estado deve ser organizado segundo as exigências do mercado, ao contrário do neoliberalismo progressista que crê na democracia como força política propulsora capaz de estabelecer regulações sobre a exploração econômica dentro da sociedade.

\section{Considerações finais}

A ideologia tem partido, a retórica não. Isso significa que a ideologia na qual o discurso político se sustenta pode gerar pontos de vista retóricos diferentes sobre a identidade do currículo. Por exemplo, uma mesma proposta curricular como a BNCC é considerada retrógrada tanto pelos pósmarxistas quanto neoliberais que negam sua validade emancipatória mediante o argumento de que a homogeneização dos saberes produz a ignorância pela eliminação do debate. Já os defensores da Base dentro dos mesmos movimentos políticos, dizem que sua aprovação corresponde a um progresso para a sociedade porque a educação é um fenômeno de massa que se dispersa por diferentes esferas e instâncias de decisão. Assim, as políticas públicas voltadas para a organização espaço-temporal do currículo favorecem seus efeitos emancipatórios.

No entanto, tanto os neoliberais quanto pós-marxistas parecem estar cegos diante dos significados mais amplos do discurso segundo o qual a 
Base foi produzida. Seus autores são membros destes dois estratos básicos do pensamento pós-moderno, cujas ideologias estão hoje presentes de forma homogênea no debate democrático da política brasileira. Por ignorância, é mais provável, a catacrese criada pelo uso do direito como dever corresponde a um sofisma retórico que subverte todas as ideologias. Pior, ela direciona o sentido aparente do discurso político para a hegemonia profunda que alimenta as disputas dadas no cerne do neocapitalismo pósindustrial da sociedade da informação: acumulação do capital simbólico, consumismo tecnológico, redução da luta de classes à disputa individual de um contra o outro, abertura de novos mercados pela afirmação das identidades sexuais, étnicas, religiosas, de gênero, etc.

\section{Referências}

AGUIAR, Márcia Ângela. Discussão sobre currículo é anterior à proposta da Base. Brasília, Ministério da Educação, 07 de março de 2016. Entrevista concedida ao Portal do MEC. Disponível em: <http://portal.mec.gov.br/component/content/ article?id=34521>. Acesso em: 25 mar. 2016.

ALVES, Nilda. Sobre a possibilidade e a necessidade curricular de uma base nacional comum. Revista e-Curriculum, São Paulo, v. 12, n. 3, p. 1474-1479, 2014. Disponível em:

<http://revistas.pucsp.br/index.php/curriculum/article/download/21664/1594 8>. Acesso em: 30 out. 2015.

ARISTÓTELES. Retórica. 2. ed. Lisboa: Centro de Filosofia da Universidade de Lisboa / Imprensa Nacional - Casa da Moeda, 2005.

AS CONTRIBUIÇÕES DE PAULO FREIRE para a Educação Crítica na Contemporaneidade. Vídeo da entrevista concedida por Michael W. Apple à Cátedra Paulo Freire da Pontifícia Universidade Católica de São Paulo PUC/SP. São Paulo: Estúdio da TV PUC, Agosto de 2006. Duração: 26:51 min. Disponível em:

<http://marxismoemarxistas.blogspot.com.br/2014/05/entrevista-michaelapple-o-legado-de.html\#!/2014/05/entrevista-michael-apple-o-legadode.html>. Acesso em: 27 Set. 2016.

APPLE, Michael W. Ideologia e currículo. 3. ed. Porto Alegre: Artmed, 2006. 
ALTHUSSER, Lovis. Ideologia e aparelhos Ideológicos de Estado: notas para uma investigação. Lisboa: Editorial Presença / Martins Fontes, 1980.

CONSERVADORISMO. In: WIKIPÉDIA, a enciclopédia livre. Flórida: Wikimedia Foundation, 2016. Disponível em: <https://pt.wikipedia.org/w/index.php?title= Conservadorismo\&oldid=46604486>. Acesso em: 8 set. 2016.

DELEUZE, Gilles. Diferença e repetição. 2 ed. Rio de Janeiro: Graal, 2006.

DERRIDA. Jacques. A escritura e a diferença. São Paulo: Perspectiva, 1995.

DERRIDA. Jacques. Carta a um amigo japonês, 2005. In LOPES, Alice Casimiro. Por um currículo sem fundamentos. Linhas Críticas, Brasília, DF, v.21, n.45, p. 445-466, mai./ago. 2015. p. 450.

DERRIDA. Jacques. Gramatologia. São Paulo: Perspectiva, 2006.

GIROUX, Henry. Teoria crítica e resistência em educação: para além das teorias da reprodução. Petrópolis: VOZES, 1986.

LACLAU, Ernesto. New reflections on the revolution of our time, 1990. In LOPES, Alice Casimiro. Por um currículo sem fundamentos. Linhas Críticas, Brasília, DF, v.21, n.45, p. 445-466, mai./ago. 2015. p. 450.

LACLAU, Ernesto. Nuevas reflexiones sobre la revolución de nuestro tiempo.

2. Ed. Buenos Aires: Nueva Visión, 2000.

LACLAU, Ernesto. La razón populista. $1^{a}$ ed. $6^{a}$ reimp. Buenos Aires: Fondo de Cultura Económica, 2011.

LOPES, Alice Casimiro; MACEDO, Elizabeth. Teorias do currículo [livro eletrônico]. São Paulo: Cortez, 2013.

LOPES, Alice Casimiro. Por um currículo sem fundamentos. Linhas Críticas, Brasília, DF, v.21, n.45, p. 445-466, mai./ago. 2015.

MACEDO, Elizabeth. Base Nacional Curricular Comum: novas formas de sociabilidade produzindo sentidos para educação. Revista e-Curriculum, São Paulo, v. 12, n. 3, p. 1530-1555. 2014. Disponível em: <http://revistas.pucsp. br/index.php/curriculum/article/view/21666>. Acesso em: 30 out. 2015.

MARCHELLI, Paulo Sérgio. Da LDB 4.024/61 ao debate contemporâneo sobre as bases curriculares nacionais. Revista e-Curriculum, São Paulo, v. 12, n. 3, p. 1480-1511, 2014. Disponível em: 
<http://revistas.pucsp.br/index.php/curriculum/article/view/21665>. Acesso em: 30 out. 2015.

MARCHELLI, Paulo Sérgio. Educação, trabalho e vulnerabilidade social: Reflexões sobre os Jovens Excluídos do Ensino Médio no Brasil. Tempos e Espaços em Educação, São Cristóvão, Sergipe, Brasil, v. 9, n. 19, p. 129-146, mai./ago. 2016. Disponível em:

<http://www.seer.ufs.br/index.php/revtee/index>. Acesso em: 30 out. 2015.

MEC. Base Nacional Comum Curricular: proposta preliminar - segunda versão revista. Brasília: MEC/SEB. Abril 2016. Disponível em:

<http://basenacionalcomum.mec.gov.br/\#/site/inicio>. Acesso em: 30 out. 2016.

MERCADANTE, Aloizio. Seminário Base Nacional Comum Curricular em ação: Formação de atores nacionais. Ministério da Educação, Brasília, 23 de fevereiro de 2016. Depoimento apresentado na abertura do evento.

Disponível em: <https://undime.org.br/noticia/29-02-2016-10-48-undimeparticipa-de-seminario-para-discutir-a-base-nacional-comum-curricular-embrasilia>. Acesso em: 26 mar. 2016.

MINOGUE, Kenneth. El populismo como movimiento político, 1969. In LACLAU, Ernesto. La razón populista. $1^{a}$ ed. $6^{a}$ reimp. Buenos Aires: Fondo de Cultura Económica, 2011 . p. 24.

MOTTA, Luiz Eduardo; SERRA, Carlos H. Aguiar. A ideologia em Althusser e Laclau: diálogos (im)pertinentes. Sociologia e Política, Curitiba, v. 22, n. 50, p. 125-147, jun. 2014.

PONCE, Branca Jurema. O Tempo no Mundo Contemporâneo: o tempo escolar e a justiça curricular. Educação e Realidade, Rio Grande do Sul, v. 41, n. 4. p. 1141-1160, out./dez. 2016. Disponível em: <http://seer.ufrgs.br/index.php/educacaoerealidade/article/view/ 60533/38821>. Acesso em: 30 out. 2016.

PROGRESSISMO. In: WIKIPÉDIA, a enciclopédia livre. Flórida: Wikimedia Foundation, 2016. Disponível em: <https://pt.wikipedia.org/w/index.php?title= Progressismo\&oldid=46642134>. Acesso em: 17 set. 2016.

\section{SOBRE O AUTOR:}

\section{Paulo Sergio Marchelli}

Doutor em Educação pela Universidade de São Paulo, professor do Departamento de Educação do Campus Professor Alberto Carvalho da 
Universidade Federal de Sergipe (DEDI/UFS) e do Programa de PósGraduação em Educação da Universidade Federal de Sergipe (PPGED/UFS). Grupo de Pesquisas Interdisciplinares em Secretariado (GPISEC). E-mail: paulomarchelli@hotmail.com.

Recebido em: 23 de setembro de 2017. Aprovado em: 18 de novembro de 2017. 